\title{
Withdrawing hydration and feeding in a person living in vegetative state: an approach from medical, anthropological and ethical perspectives
}

\begin{abstract}
In mid-2013, a small city in southwestern Argentina lost its provincial quietness after two sisters required withdrawing hydration and nutrition from their 49-year-old brother who had been living in vegetative state for decades. The sisters alleged their brother would not have wanted living so; however, they possessed no written proofs, but only a testimony of a conversation the siblings would have had when they were teenagers. In contrast, the employees of the nursing home, who actually were caring for the brother, rejected the sisters' request arguing that the brother was still alive, and withdrawal of water and food will directly provoke his death. Because of disagreement between the relatives and caregivers, the case was brought to the Court what caught the attention of the media that soon turned this intimate story into a national sensation, and split the locals into adversaries. Ethics committees, specialists, and religious authorities were asked for opinions. On request of some local people interested in understanding the case, the Institute of Bioethics at Catholic University of Argentina released a document that has served as a reference for the current case report. By analyzing the facts from medical, anthropological and ethical perspectives, the following case report focuses on aspects such as difficulties in making consciousnesscentered diagnosis and conceiving new states of life with different neurological status; association of functional impairment and worthiness of a personal life; robustness of advance directives made without knowing circumstances; ethical standard and human nature, among others.
\end{abstract}

Keywords: end-of-life, bioethics, palliative cares, unresponsive patient, vegetative state, withdrawing hydration
Volume I Issue 4 - 2017

\section{Lenin de Janon Quevedo}

Instituto de Bioética, Pontificia Universidad Católica Argentina, Argentina

\begin{abstract}
Correspondence: Lenin de Janon Quevedo, Instituto de Bioética, Pontificia Universidad Católica Argentina, Av. Alicia Moreau de Justo 1600, Ed. San José, $3^{\text {er. }}$ piso, CI I07AAF, Ciudad de Buenos Aires, Argentina, Tel 54I I 43490284, Email Idejanonquevedo@uca.edu.ar
\end{abstract}

Received: September 20, 2017 | Published: October 04, 2017
Abbreviations: DAM, fictitious name of the person this case is referring to; LLNS, low-level neurological state; MCS, minimally conscious states; VS, vegetative state

\section{Introduction}

In the austral winter of 2013, the Patagonian city of Neuquén was passing through turbulent times. Quietness of this provincial city, 723 miles to the southwest of Buenos Aires, was broken as a result of the request of two sisters who claiming for withdrawing hydration and nutrition, and stopping prescribing antibiotics for their 49-year-old brother who had been living in vegetative state (VS) for 19 years. In a letter addressed to largest daily newspaper of Argentina, El Clarín, one of the sisters affirmed that her brother D.A.M. "would not have wanted to live this way", and "nothing we can do could change the fact that D.A.M. had gone away even long time ago". ${ }^{1}$ However, the caregivers of the nursing home where D.A.M. had been placed, who actually were caring for him, refused to obey the petition of the sisters arguing that D.A.M. was still alive, and they would let him no die of neither hunger, nor thirst. Hence, the case was brought to the courts where D.A.M's sisters had to prove the brother's wish; despite they did not possess any written document as evidence.

D.A.M.'s story reached national relevance as the media showed interest on coverage. Accordingly, very touching testimonies from both the relatives and caregivers were published, and family intimacy was exposed without restrictions. Moreover, renowned specialists and recognized ethics committees were asked on the issue; and the catholic Archbishop of Neuquén pleaded with the family to trust on the Church, and employees of the nursing home, to care for D.A.M. until the arrival of "the conclusion of his course on this earth in a natural way". Even it appeared that all the country was scientifically and emotionally in conditions to debate about vegetative or minimally conscious states (MCS). By that time, the dwellers of Neuquén were literally split into two groups: the supporters of the idea that dignity meant helping him to die, and those who thought there was no way to uphold dignity by provoking death via dehydration and starvation. By request of a group of the locals, the Institute of Bioethics at Pontifical Catholic University of Argentina released a position document that analyzed the facts from medical, anthropological, and ethical perspectives, ${ }^{2}$ and which has been a reference for the following case report.

\section{Case presentation}

\section{Background}

At the age of 30, D.A.M. survived a motorbike accident that caused impairment of consciousness. Two months later, doctors first mentioned a new diagnosis: vegetative state, and a few weeks from that, D.A.M. was discharged from the hospital. At the beginning, the parents cared for D.A.M. in the family house, but cares became difficult after his mother passed away. Then, D.A.M. was placed in a nursing home where his father used to visit him every single day, 
until the father also died. Thus, the sisters became legal guardians, as they were the only remained relatives. The sisters asserted that the will of their brother would be not to live in that way, but they had no written evidence except a testimony of one sister where a 14-year-old D.A.M., talking about Karen Ann Quinlan story, would have told her: "if something like that happens to me, let me die". The sisters went to the district Justice after the caregivers refused to obey the request for withdrawing hydration and nutrition. The Court ruled in favor of the relatives; yet, the Defender of Disabled People appealed the decision. Actually, the last diagnostic update had been done five years earlier, in 2009, and it was necessary rechecking it. By words of the caregivers D.A.M. was able to scratch, obey an order by squeezing his hand, smile to music he liked listen to, express fatigue on his face, and being sensitive to affections. The health workers perceived that it was non-reflexive behavior, what strengthened the idea it was intentional responsiveness to some tasks.

As the case went forward within the justice, the newspapers were revealing private information, and the public opinion was taking a position. The legal battle, the media, and the relatives and caregivers claiming to accomplish what they considered right, converted very sensitive information-once kept under an intimate personal sphereinto public opinion. At that time, it seemed that was no longer relevant what D.A.M. would have thought about his current life. Nor whether could he have preserved a remote ability to make own decisions. Perhaps human life was being simplified to a court battle. In order to preserve privacy of all involved people, the mentioned position document that served as a reference for the current case report took into account only information of public knowledge. ${ }^{1,3,4}$

\section{Medical perspective}

From a medical point of view, the essential human attributes are a result of the integrative function of consciousness. Integrative function is characterized by two dimensions: arousal or wakefulness (i.e., ability to awake); and awareness (i.e., content of consciousness). Only after having lost forever the ability for awaking-in other words, in an "irreversible" way-a human being is certified as dead. ${ }^{5,6}$ Although the people in VS preserve the ability to wake up, they are unaware of the surrounding world owing to impaired content of consciousness. Consequently, those people are handicapped to express their thoughts and feelings. Nevertheless, no one can guarantee that a person living in VG is unable to think or feel. The VS is just a part of a wide-ranging list of disorders of consciousness where MCS is also included. It has been observed that people in VS can move towards a state of MCS, and therefore start communicating and interacting with family environment. ${ }^{7}$ That movement occurs because awareness and unawareness should been seen as part of a continuum capable of "turning on" at any time. ${ }^{8}$ The adjectives "persistent" or "permanent" usually added to the diagnosis are confused since they involve a misleading connotation of irreversibility. ${ }^{9}$ The word "vegetative" is pejorative, and implies an inexistent quality of the human life. ${ }^{10}$ Instead, the experts have suggested replacing the word "vegetative" with a more realistic term such as "Post Coma Unresponsiveness" "Unresponsive Wakefulness Syndrome". 12,13

Moreover, subjective dimension of consciousness is almost impossible to determine only from an external observation what, besides several clinical difficulties in assessing both consciousness and cognitive functions, makes difficult to understand the VS as a whole. Accordingly, it is hard to determine, or rule out, thinking or feeling of a person living in low-level neurological state (LLNS). Likewise, there is no scientific evidence that certainly affirm a person in VS lacks of thirst or hunger; on the opposite, neuroimaging studies have observed pain sensations would be generated by thirst. ${ }^{14}$ What is more, subjective thinking has been likely to persist in VS according to physiological and pathological findings. ${ }^{15}$ In addition, people living in VS do maintain the functions of hypothalamus and brainstem, as well as stability of vital signs, and autonomous breathing. Namely, a person in VS is perfectly able to live independently from mechanical ventilation, or any kind of life support-bearing in mind that life support means substituting an organ whose physiological impairment threatens the individual's life.

Detailed observation of the behavior and responsiveness to external stimuli compose important diagnostic criteria in VS, what demands frequent and periodic observations where the caregivers play an irreplaceable role as evaluators, no matter that the observations are always subjective determinations. Since the caregivers can observe when a person in VS interconnects with environment, their testimonies are very helpful, especially because the connections are mostly unsteadying or slightly evident. ${ }^{11,12,15}$ Aside from complexity of physical examination, the logic of diagnosis of VS has a conceptual problem: "lack of evidence of awareness" is deemed as "evidence of the lack of awareness". Moreover, diagnostic errors are quite common-reach up to $40 \%{ }^{12}$-what might explain why many people living in MCS are misclassified as VS. Add to this that the idea of "irreversibility" is nothing more than statistical data, and the bias while making prognosis has been associated with pessimism of the doctors. ${ }^{16}$ Perhaps that clarifies why a majority of the doctors believes that VS is worse than death; the people in VS should be considered as deceased ones, ${ }^{17}$ and the unexpected and largely documented cases of patients with recovery of cognitive function have no scientific relevance. $^{18}$

We must recall that people living in VS or MCS should not be considered as "incurable" simply for having lost content of consciousness. It has been observed that after stabilization of the symptoms, and definition of the neurological impairment, those people start living under a new non-pathological state of health. Put differently, VS and MCS do not fit within the conceptions of health disorders classically conceived as illness, disease and sickness. ${ }^{19}$ In particular, these states lack of enough subjectivity for expressing illness; show difficulties in standardize diagnosis making what is indispensable for disease definition; and have a distorted idea of sickness as a result of minimal social participation of disabled individuals. Besides, the states neither fully meet inclusion criteria of terminal illness ${ }^{20}$ as they possess stable life conditions without multifactorial symptoms worsening day after day. Furthermore, LLS is not a consequence of failed specific treatments; and whether intercurrences do not produce health deterioration or death, the people in LLS might live further than six months-period that exceeds the maximum survival time considered as the limit for terminally ill patients. Finally, and without doubting about suffering of the families, there is no evidence affirming that people in LLNC perceive looming of death, nor how the emotions could affect.

\section{Anthropological perspective}

Medicine and other empirical sciences agree that they express just a part of human suffering: the illness of the body. Nevertheless, suffering goes beyond the boundaries of physical illness-it is always more complex and multidimensional. Suffering's roots go also back to the very origin of humanity; and so, this family has been able to read the history of humanity through the story of D.A.M. 
After many years of caring for a disabled loved one, it is perceived that the relatives carry moral suffering on their shoulders, and their souls are overwhelmed with sorrow. Despite that, firstly the parents, and secondly the sisters, have decided keeping alive D.A.M. It is time we, the whole community, to start caring for all of them. The moment for the people outside the family circle to become in the caregivers who provide the support the family has been calling for in a subtle unnoticed way. In contrast, the community attempts showing solidarity by replicating a behavior observed among the parents of young children who must face critical illness, and are not mature enough to utter what they suffer. Because of inexplicability of such situations, the overwhelmed parents explain what they are suffering instead of figuring out ability of their children to cope with that. ${ }^{21}$ As a community, we actually do the same. Rather than talking about suffering of the vulnerable ones, we speak out what they are making us suffer: uncertainty, powerlessness and fears arising from ignorance. Certainly, it is understandable to avoid being harassed by sufferings, but it is impossible to spend the whole life fleeing from them, or ignoring the things bothering us. Doing so would mean to fall prey to the dangerous feeling of self-commiseration ${ }^{22}$ which justifies disposing the life of everyone who reminds us how vulnerable we are, and what a deep we can suffer.

Every human life has the same quality and admits no graduations. Both the presence and absence of a personal life constitute absolute entities. In this sense, it is sufficient to realize that nobody could be alive and dead at the same time. In addition, the quality of life must not be mistaken with the "value of life": a single and universal worth for all human beings regardless of phase of growth, or the precarious and burdensome life conditions of a particular person. Pessimism when making prognosis would be equivalent to conceiving the human life just as a sum of perceptible actions. This conception stems from the functional mechanistic worldview that highly influence on end-oflife (EOL) decision-making. If indeed this worldview was applied to appreciate people unable to validate the expression of consciousness, many flesh-and-blood beings would be labeled as nonexistent.

Setting aside the empirical evidence, the human being never stops functioning and that is confirmed through a large amount of nonmaterial realities infeasible to be quantitatively measured, e.g., the moral values or the advance directives. But in this story would appear that there is not a suitable expressed directive; however, judging by the long-lasting cares the relatives have provided, the family surely has not wished other than cherishing the life of D.A.M.

\section{Ethical perspective}

First, it should be noted that a proper ethical judgment has to be relied on trustworthy data, and technically unobjectionable medical procedures. While making diagnosis, the physicians cannot omit that a patient, as a person, is a complex wholeness existing even in conditions of unconsciousness, in special, when absence of awareness is just a presumed fact. Moreover, since human existence implies exchange of energy and matter with surrounding environment, liquid and food withdrawing signifies a major threat for human existence, that is, a real possibility of extinguishing the very human life-the greatest good of the human society on which all other goods are founded.

Additionally, whenever we say hydration and nutrition, we are saying medical procedures. Hydration and nutrition, as any medical action, hold specific therapeutic goals to be performed by a team specifically trained for that. Here, the core discussion is concerning on the kind of liquid and nutrient supplies, as well as the ways for accessing: venous line or the gastrointestinal tract. In addition, the patients, and sometimes the surrogates, have right to refuse receiving hydration and nutrition when they take these procedures as "extraordinary" on the ground of their personal beliefs, decision that should not be judged as unethical.

Nevertheless, the administration of liquid and food through a tube inserted into a person living in LLNS should be compared with giving drinking and eating to a fellow human being, and not hydrating and feeding a patient. It is not a simple semantic detail: giving to drink and eat are human actions planned and performed by anyone-no matter the training-that allow a person to calm thirst and hunger by virtue of elementary needs-or rights-linked to existence of the humans as a species. For a person living in LLNS, those existential rights imply avoidance of dehydration, malnutrition, and pain caused by them. Hence, when talking about giving to drink and eat, we are not talking about medical procedures. Nor are we debating on the ways of accessing because the sole available access is the digestive tract.

Second, unlike the animals that are limited by the objects disposed by nature to look for food, the humans have learned to overcome the limits by creating tools to make food more accessible. The use of devices for drinking and eating goes back to immemorial times, and as such, one could say tool using has turned into the very nature of the modern humans. Accordingly, tool-assisted passing of water and food in a person living in LLNS is not supererogation, but an elementary need. Namely, usage of a nasogastric tube in an unconscious person is as either ordinary as usage of a spoon or drinking straw by a conscious person, since in both situations are fulfilled the needs for existence of a particular individual regardless their lost functions.

Further, whatever the conception of human dignity may be, it has always to consider the already existing life. It is no wonder that the health workers, as well as many other people, reject withdrawal of assistance for the mere reason that the tube allows the users-caregivers and patients-to execute what has been an ethical imperative across the history of humanity: preservation of the human existence. Therefore, it is comprehensible to think that the contradiction of that imperative is going to be taken as ethically unacceptable.

On the same grounds, should also not be taken as medical procedures such actions as clearance of the airways, treatment and prevention of pain, changes of posture, hygienic bath and change of linen, and even the usage of sensorial stimulation by listening to music, conversations or caresses.

Third, when committing these actions, the individuals are following the idea of the Good Samaritan: a human behavior described not only in the Scriptures, but also in other moral philosophies no matter the culture or believes. The Good Samaritan approach is a path to grant the fellow humans elemental goods, particularly, such nonmaterial goods that we all deserve-being loved, shielded and cared for. Had it not been for the love and care, nobody could have come about what he or she really is. For that reason, it is said that the Good Samaritan approach grants so-called the "essential" cares. Among those cares as well are to give drink and eat, what differs from hydrating and nurturing.

Then, stop giving the essential cares will mean to commit actions against humanity therefore will lack of ethically legitimacy. Now, there is no doubt that some interventions are needed to place a device such as the nasogastric, gastrostomy or jejunostomy tubes; however, the issue is not avoiding using the devices, but selecting an ethical 
guide. Here, the ancient duty of "do no harm"-more precisely "to maximize prevention of harm"-is the most appropriate principle to use.

By contrast, implementations of life-support techniques, invasive treatments and diagnostic tests, surgical interventions, antibiotic prescriptions, among others actions aimed to reverse what is reversible, do imply medical procedures. They should be applied according, besides harm avoidance, to the approach on the proportional and ordinary means. ${ }^{23}$ In conditions of subrogation, the person who knows most about willingness of the subrogated should evaluate the ordinary means-the family in the current case.

Notwithstanding, it is arguable whether the decisions by subrogation are exclusively guided by the principle of the best interest of the subrogated, a trait that gives rise to uncertainty from bioethical, legal and social perspectives, in particular at the EOL. Sufficient is to mention that unrestricted subrogate decisions have provoked controversy more than once. Nor must we also forget that when sufferings lead us to put end with a person's life by means of stopping giving water, and food, we will commit the unethical act of euthanasia.

As a community, we will accomplish a huge step forward if can see beyond our noses finding out that solidarity means the preservation of the totality-of the whole humanity. Inside this wholeness, there is room for everybody, especially for the most fragile and vulnerable.

\section{Discussion}

This case has raised such questions as the limit of intrusion of public opinion into the familiar intimacy, or complexity of patientmedical relationship at the end of life. Yet, without putting aside the importance of all observed issues, I would like focusing on the following three topics:

i. The medical fact of making sensitive decisions based upon untrustworthy data.

ii. The power of the advance directives obtained on hypothetical situations and granted early in adolescence.

iii. The human life existence as ethical criterion.

Although their diagnosis has improved, many neurological disorders remain unclear in terms of progression, and prognosis; in particular, when frequent diagnostic errors reduce likelihood of establishing more real medical expectations. We do not to forget that medical expectations are not simply the doctors' opinions, but specific conclusions derived from the available objective clinical data. Communication of objective data, and the opinions drafted from them, is among the ethical duties of the physicians. The more is decreased the objectivity or accuracy of the findings, the more the risk of simplifying the medical expectations to mere personal opinions of the doctors. Likewise, it has been observed that doctors pour in their opinions the feeling of frustration when they see diminished the probabilities of reversibility and resources for curing. ${ }^{24}$ In addition, it is known that the physicians confront fears and anxieties (for instance, death-related fears) when dealing with incurable patients, or in context of the EOL. ${ }^{25,26}$ Perhaps that explains the doctors attitudes - and opinions - toward the people living in VS, and why those people are portrayed as already deceased. ${ }^{17}$ In view of the fact that doctors opinions are fundamental to make sensitive decisions, ${ }^{27}$ it is noteworthy the impact of medical bias when advising the family decision-makers of the people in LLNS. ${ }^{16}$ It is expected, then, the physicians to express prognosis humbly recognizing knowledge they do not possess. Here, humility connotes not a supererogation, but a duty derived from professional honesty.

Concerning the advance directives, one could agree that the family is a natural representative that pursues the best interest of a person unable to utter their thoughts. Nevertheless, the matter in this story concerns about feasibility of a decision made without knowing circumstances under which that decision will turn into reality in the future, particularly, when it was made in very young age as in the teen years. Let us remember that ignorance is a coercive factor that makes the decisions be weak and infeasible, for they are technically inapplicable, and sometimes contradict the very goals of medicine. ${ }^{28-31}$ Indeed, the more we know the freer and more legitimate our elections are-what proves the fact that human liberty is always executed within concrete, and not hypothetical circumstances. At the end-of-life, legitimacy of decisions is closely associated to its feasibility both technical, and ethical.

Regarding ethical aspects, this case illustrates that the employees of the nursing home have set the course of life as a standard of correctness when making sensitive decisions on caring for the ill and disabled people. Nature (physis) as ethical boundary has been a conception embraced by the humans since ancient medicine. ${ }^{32}$ Thus, the dictates of nature served as the rule to qualify goodness in health caregiving for centuries, until individual autonomy emerged as the chief ethical criterion after free will became the most appreciated trait of human nature. Likewise, we must not forget that only a living person maintains ability to decide by their self, even though this might exist as a potentiality. At this point, the caregivers had warned that D.A.M.'s reactions to surrounding world could be intended responses to complex tasks, among those, the possibility to make decisions; and this would be aligned with data suggesting that a person in LLNS can "regain consciousness". 18,33

Then, how could the caregivers have reacted in the absence of an evident expression of willingness? I believe, under such circumstances they could not have reacted other than through respecting the physis, in other words, defending the physical life. This robust ethical criterion ensures that harm is avoided when the caregivers have to face uncertainty; and, in this respect, both the ancient and contemporary people would appear to agree. In practice, it means accompanying a vulnerable person to make sensitive decisions while coping tough, sometimes final, days. To this aim, palliative cares are enabled enough to play an irreplaceable role. I am sure there were left aside many topics in which the reported case has aroused interest. I am convinced that these topics will fuel analysis and discussion in the future ${ }^{1}$.

${ }^{1}$ Two years after releasing the document that served as an orientation for this case report, the Supreme Court recognized there was no written evidence endorsing D.A.M.'s wishes; and having updated forensic neurological examination, it certified that D.A.M. had lost the ability to express his willingness by own means. However, the Court admitted that the sisters had authority to testify about willingness of their brother arguing the fact they were the only relatives alive who had shared the family intimacy. Likewise, the Justices pointed out that the relatives were not authorized to decide about withdrawing in conform to their wishes. In this regard, the Justices understood the sisters were just communicating an autonomous and conscious decision made by D.A.M. in the past, and therefore hydration and nutrition should be withdrawn, because they constituted medical procedures that prolonged a state of life that D.A.M. would never have liked to live. Thereby, the Supreme Court of Argentina required the caregivers to stop giving medicines, water, and food through nasogastric tube, but not without first taking steps to avoid and relieve suffering. D.A.M. died of pneumonia the same day the definitive ruling was published [34]. 


\section{Acknowledgements}

I thank Professors Rubén Revello, Nicolás Lafferriere, and Silvia Anselmino, at the Instituto de Bioética, for their comments on the earliest version of the manuscript.

\section{Conflict of interest}

The author declares that there is no conflict of interest regarding the publication of this article.

\section{References}

1. Pepe O. Marcelo, te dejaremos ir... Diario. Dispuesto a escuchar, Clarín Opinión: 2013

2. Revello R, de Janon Quevedo L. Es lícito suspender los líquidos a una persona en estado vegetativo o de mínima conciencia? Reflexiones a propósito de un caso. Vida y Ética. 2013;14 (1):129-138.

3. Diario La Nación. La historia de Marcelo Diez, el hombre que pudo acceder a una muerte digna; 2015.

4. Luna F, Etchanique MB, Lizarzuay G. La muerte imposible de Marcelo Diez. Revista Anfibia. 2015.

5. Machado Curbelo C. Do we defend a brain oriented view of death. Rev Neurol. 2002;35 (4):387-396.

6. Machado C. Is the concept of brain death secure? In: Zeman A \& Emanuel L editors. Ethical Dilemmas in Neurology. London, UK: WB Saunders; 2000;123(11):193-212.

7. Laureys S, Boly M. The changing spectrum of coma. Nat Clin Pract Neurol. 2008;4(10):544-546.

8. Monti M, Laureys S, Owen AM. The vegetative state. BMJ. 2010;341(c3765):292-296.

9. Dolce G, Lucca LF. The Vegetative State Updated. Journal of Psychophysiology. 2010;24 (2):107-111.

10. Zasler N. Terminology in evolution: caveats, conundrums, and controversies. NeuroRehabilitation. 2004;19:285-292.

11. Boehringer VM. Estado vegetativo (post coma unresponsiveness): una condición poco compreendida. Medicina e Morale. 2010;1:75-109.

12. Laureys S, Celesia G, Cohadon F, et al. Unresponsive wakefulness syndrome: a new name for the vegetative state or apallic syndrome. $B M C$ Med. 2010;8: 68

13. von Wild K, Laureys ST, Gerstenbrand F, et al. The vegetative state-a syndrome in search of a name. J Med Life. 2012;5(1):3-15.

14. Farrell MJ, Egan GF, Zamarripa F, et al. Unique, Common, and interacting cortical correlates of thirst and pain. Proc Natl Acad Sci USA. 2006;103(7):2416-2421.

15. Cruse D, Owen AM. Consciousness revealed: new insights into the vegetative and minimally conscious states. Curr Opin Neurol. 2010;23(6):656-660

16. Rubin EB, Bernat JL. Ethical aspects of disordered states of consciousness. Neurol Clin. 2011;29(4):1055-1071.
17. Payne K, Taylor RM, Stocking C, et al. Physicians' attitudes about the care of patients in the persistent vegetative state: a national survey. Ann Intern Med. 1996;125(2):104-110.

18. Lammi ML, Smith VH, Tate RL, et al. The minimally conscious state and recovery potential: a follow-up study 2 to 5 years after traumatic brain injury. Arch Phys Med Rehabil. 2005;86(4):746-754.

19. Wikman A, Marklund S, Alexanderson K. Illness, disease, and sickness absence: an empirical test of differences between concepts of ill health. $J$ Epidemiol Community Health. 2005;59(6):450-454.

20. Guía de cuidados paliativos. Sociedad Española de Cuidados PaliativosSECPAL; 2014.

21. Montoya-Juárez R, García-Caro M, Campos C, et al. Sufrimiento en infantes con enfermedad terminal: perspectiva de padres y profesionales. Rev Esc Enferm USP. 2012;46(6):13000-1305.

22. Schooymas M. Eutanasia hoy. Humanitas. 2006;43:436-448.

23. Calipari M. The principle of proportionality in therapy: foundations and applications criteria. Neuro Rehabilitation. 2004;19(4):391-397.

24. Halpern J. Empathy and patient-physician conflicts. J Gen Intern Med. 2007;22(5):696-670.

25. Seravalli P. The dying patient, the physician and the fear of death. $N E n g l$ J Med. 1998;319(26):1728-1730.

26. Hamama-Raz Y, Zahava S, Ohry A. Fear of personal death among physicians. Omega. 2000;41(2):139-149.

27. Braun U, Ford M, Beyth R, et al. The physician's professional role in end-of-life decision making: voices of racially and ethnically diverse physicians. Patient Educ Couns. 2010;80(1):3-9.

28. Blondeau D, Valois P, Keyserlingk E, et al. Comparison of patients' and health care professionals' attitudes towards advance directives. $J \mathrm{Med}$ Ethics. 1998;24(5):328-335.

29. Richter J, Eisemann M, Zgonnikova E. Doctors' authoritarianism in endof-life treatment decisions. A comparison between Russia, Sweden and Germany. J Med Ethics. 2001;27(3):186-191.

30. Barnato A, Herndon M, Anthony D, et al. Are regional variations in endof-life care intensity explained by patient preferences? A study of the US Medicare population. Med Care. 2007;45(5):386-393.

31. Periyakoil V, Neri E, Fong A, et al. Do Unto Others: Doctors' Personal End-of-Life Resuscitation Preferences and Their Attitudes toward Advance Directives. PLoS ONE. 2014;9(5):e98246.

32. Laín Entralgo P. Historia de la Medicina. Barcelona, España: Salvat Editores; 1978. p. 132-135.

33. Bender A, Jox R, Grill E, et al. Persistent vegetative state and minimally conscious state. a systemic review and meta-analysis of diagnostic procedures. Dtsch Arztebl Int. 2015;112(14):235-242.

34. Centro de información judicial. La Corte Suprema reconoció el derecho de todo paciente a decidir su muerte digna; 2015. 